\title{
Air Pollution Tolerance Indices (APTI) of Six Ornamental Plants Commonly Marketed at "Ebano Tunnel" Floral Market, in Enugu Urban, Enugu State, Nigeria.
}

\author{
*Otuu, Fred Chibuisi ${ }^{1}$, Inya-Agha Stella Ifeoma ${ }^{2}$, Ani, Uchenna Godwin ${ }^{3}$, Ude, \\ C.M ${ }^{4}$, Inya-Agha, Tochukwu $\mathrm{O}^{5}$ \\ Drug Delivery/Environmental Research Unit, Dept. of Pharmaceutics, University of Nigeria Nsukka. \\ Dept. of Pharmacognosy/Environmental Medicine, University of Nigeria Nsukka. \\ Dept. of Estate Management, Enugu State University of Science and Technology, Enugu. \\ Dept. of Applied Bio-Chemistry, Enugu State University of Science and Technology, Enugu. \\ Dept. of Medical Laboratory Sciences, University of Nigeria Enugu Campus.
}

\begin{abstract}
Enugu Urban Local Government Area is the capital of Enugu State in the South Eastern Geopolitical Zone of Nigeria. "Ebano Tunnel" is an important link road between the two busiest parts of Enugu Urban- the Ogui Urban area and the Abakiliki road/GRA. Owing to this strategic location, the "Ebeano Tunnel", recently is witnessing massive floral market where ornamental plants are displayed. Six species of ornamental plants commonly marketed (Ficus, Hibiscus, Ixora, Phitis, Toja and Red rose) were evaluated for their Air pollution Tolerance Indices (APTI). The APTI of each plant was computed from four physiological and bio-chemical parameters namely: - $P^{H}$ of the leaf extract, Relative water content, Ascorbic acid and chlorophyll content. The APTI values ranged between 9.04-15.26 on Hibiscus and Toja respectively. The ornamental plants with high APTI (Tolerant) are recommended for use in domestic, industrial and urban land scapping both for their aesthetic values and phytoremediation potential of air polluted environment, while the plants with low APTI (Sensitive) are to be used as bio-indicators of environmental air quality.

Keywords: Ornamental Plants, APTI, Land scapping, phytoremediation.
\end{abstract}

\section{Introduction}

Recently, there is a significant development in public and private infrastructural setup, vehicular activities and population increase in Enugu State in general and Enugu Urban in particular. The good governance of the present administration and the relative good security system in the Enugu State has attracted massive investment in real estate and manufacturing industries. This increases human and vehicular population with the resultant anthropogenic-induced environmental pollution of the domestic, industrial and urban air quality. In line with the growing real estate industry is the sharp rise in horticultural and floral activities.

In the developing countries such as Nigeria, land-scapping and street-scapping are more for aesthetics than public health effect with the result that the property developers and individuals are more attracted to colours without regards to the ability of the plant to withstand stress-associated with environmental pollution of anthropogenic origin. Only recently have very few individuals and government agencies realized the significant public health benefits associated with ornamental plants and are therefore, beginning to select them on the basis of beauty and longevity.

Air Pollution Tolerance Index (APTI) in plants is the evaluation of the susceptibility level of plants to air pollution (pollutants), using four parameters, namely ascorbic acid content, chlorophyll, relative water content, and $\mathrm{pH}$ value of leaf extract, (Agarwalet al., 1991). Plants with high index values are more tolerant to air pollutants.

Ordinarily, tolerance of plants to air pollution can be measured by simple symptoms such as visible injury on the plants, but it can be correctly evaluated by calculating the tolerance index of plants to air pollutants. Plants are classified into three categories of sensitivity: APTI $<10$, sensitive, APTI 10- 16, intermediate, APTI $\geq 16$ tolerant, (Agarwal and Singh, 1991). This study evaluated the Air Pollution Tolerance Indices of six Ornamental plants marketed at the floral garden along "EbanoTunel", off Abakiliki road G.R.A Enugu. Recently there is a high degree of awareness on the significance of plants in screening UV lights and particulate dust from having direct access to human health, so that the use of ornamental plants by land scappers and architects in residential buildings, industrial sites and public parks has gone beyond beautification to include health protection. The ability of plants to serve these purposes is influenced by their air pollution tolerance indices, (Kousaret al., 1999). This study was predicated on the above. Sensitive species are more useful as bioindicators and tolerant species are more appropriate as phyto-remediating agents in polluted environments. The bio-indicators assist in planning the urban cities to avoid pollution (Ghosh, 1992). 
Plants play significant roles in the monitoring and maintenance of the ecological balance through the cycling of nutrients and gaseous elements such as Nitrogen, carbon dioxide, Oxygen as well as provision of adequate leaf area for sedimentation, absorption, adsorption and accumulation of pollutants to reduce the pollution level in the air environment, (Lovett and Lindberg, 1993). Air pollution is one of the major environmental problems threatening the sustainability of lives of all organisms. Mitigation of air pollution is a significant health challenge that calls for integrative efforts. Since plants serve as a pollution sink because of their folia arrangement, evaluation of tolerance ability of plants to air pollution is an important tool in selecting plants that are suitable for remediation and monitoring of air pollution. There are various ways and means to mitigate the urban environmental pollution. Planting of trees and shrubs for abatement of pollution and improvement of environment is an effective way and well recognized throughout the world (Agbeire and Efaienrhe, 2009).

The response of plants to air pollution at physiological and biochemical levels can be understood by analyzing the factors that determine their resistance and susceptibility (Agbeire, 2009; Enete and Ogbonna, 2012).

Ascorbic acid content is an important parameter that may be used to decide the tolerance of plant to air pollution, because of its anti-oxidative properties, as well as its a significant role in light reaction of photosynthesis (Conklin, 2001; Singh, 2009), activation of defense mechanism (Aroraet al., 2002), and under stress condition, it can replace water from light reaction (Singh, 1991).

$\mathrm{P}^{\mathrm{H}}$ plays vital physiological roles in living organisms. Basically, enzymes which control the biological activities of living organism function well within a given small range of the $\mathrm{P}^{\mathrm{H}}$ values of their environment. Some enzymatic activities require low $\mathrm{P}^{\mathrm{H}}$ while some others require higher or even neutral $\mathrm{P}^{\mathrm{H}}$ to function effectively.

High $\mathrm{P}^{\mathrm{H}}$ may also increase the efficiency of conversion from hexose sugar to AA, while low leaf extracts $\mathrm{P}^{\mathrm{H}}$ has also showed good correlation with sensitivity to air pollution (Gostin, 2009). Photosynthetic efficiency was noted to be strongly dependent on leaf $\mathrm{P}^{\mathrm{H}}$.

Chlorophyll is the green pigment found in the chloroplasts (green plastid organelles) in photosynthetic plants. It is the molecule that absorbs sunlight and uses its energy to synthesize carbohydrates from $\mathrm{CO}_{2}$ and water. This process is known as photosynthesis in which chlorophyll because of its intrinsic ability converts radiant energy (from sunlight) into chemical energy (ATP). The molecules are specifically arranged in and around pigment protein complexes called photo systems which are embedded in the thylakoid membranes of the chloroplasts. The area of the leaf containing chlorophyll appears green due to its selectivity regarding the wavelength of the light it absorbs. Total Chlorophyll (TCh) is another parameter in APTI that is so important, (Rabe and Kreeb, 1980; Pandey, 1994). Depletion in Chlorophyll immediately causes a decrease in productivity of plant and subsequently plant exhibits poor vigor.

Plants are known to accumulate enormous quantities of water in their growth activity, and can have water content ranging from $60-200 \%$, (Lawrence and Honberger, 2007). It could even be as high as $400 \%$ in extreme cases. The weight of green plants is therefore, enormously dependent on the water content. Water as a solvent plays important roles in plant life, ranging from maintenance of body temperature to conduction of nutrient, as solvent and in metabolism. By effecting photosynthesis and translocation, gaseous pollutants may reduce carbon growth, capacity for water and nutrient uptake (Siccama, 1983). Therefore, water is a necessity for plant life. Shortage of water may cause severe stress, while high water content within a plant body will help to maintain its physiological balance under stress conditions such as exposure to air pollution when the transpiration rates are usually high.

\section{Materials And Method}

The plant samples were selected randomly from floral garden along "Ebano Tunnel", off Abakiliki road G.R.A Enugu. The plants were authenticated by a Taxonomist, Mr. Ozioko of Bio-resource Laboratory, Nssuka.

\subsection{METHODOLOGY}

\section{Relative Water Content (RWC)}

The method described by Singh (1977) and Agbaire and Esiefarenrhe (2009) was applied to determine and calculate relative leaf water content as follows:

Fresh leaf sample was weighed and recorded as FM - fresh mass. It was floated in distilled water inside a closed petri-dish, at a room temperature for $24 \mathrm{hrs}$. At the end of the incubation period, leaf sample was wiped dry to obtain the turgid mass (TM). It was placed in a preheated oven at $80^{\circ} \mathrm{C}$ foe $48 \mathrm{hrs}$. Thereafter the leaf was weighed to obtain the dry mass (DM). The relative water content was calculated using the formuler:-

$\begin{array}{llllllll}\text { RWC } & =\mathrm{FW}-\mathrm{DW} & \mathrm{x} & 100 & & \\ \mathrm{FW} & = & \text { Fresh Weight } & & \text { TW } & & \text { DW }\end{array}$


DW $\quad=$ Dry Weight

TW $\quad=$ Turgid Wight

\subsubsection{DETERMINATION OF LEAF $P^{\mathrm{H}}$}

The $\mathrm{P}^{\mathrm{H}}$ was determined by the Direct Reading Engineering Method (DREM), using digital $\mathrm{P}^{\mathrm{H}}$ meter. The leaf extract was made by cold maceration of the leaf with de-ionized water, filtered through an ashless filter paper, and the filtrate used for $\mathrm{P}^{\mathrm{H}}$ determination. The $\mathrm{P}^{\mathrm{H}}$ meter was pre-calibrated prior to its usage, using buffer solution of $\mathrm{P}^{\mathrm{H}} 4$ and 9 . The $\mathrm{P}^{\mathrm{H}}$ electrode was carefully dipped into the filtrate in a $10 \mathrm{ml}$ beaker. The value displayed on the crystal liquid display panel (CLD) of the $\mathrm{P}^{\mathrm{H}}$ meter, was taken as the true $\mathrm{P}^{\mathrm{H}}$ value. The exercise was triplicated, and the average of the three readings used.

\subsubsection{ASCORBIC ACID DETERMINATION}

Ascorbic Acid was determined by the titremetric method after AOAC, 2005. The ascorbic acid was extracted with $20 \mathrm{ml}$ of distilled water, in $30 \mathrm{ml} \mathrm{H}_{2} \mathrm{SO}_{4}$ and $0.5 \mathrm{~mol}$, oxalic acid. $2 \mathrm{~g}$ of the plant sample was added with the mixture and stirred thoroughly for 10 mins. The mixture was filtered and $10 \mathrm{ml}$ of the filtrate titrated against $0.05 \mathrm{~mol}$ iodine solution, using starch mucilage as indicator to end point. The ascorbic acid value was calculated from the relation:

$1 \mathrm{ml} 0.05 \mathrm{~mol}$ iodine $=0.008806 \mathrm{~g}$

$$
=8.806 \mathrm{mg}
$$

\subsubsection{CHLOROPHYLL DETERMINATION}

This was determined by the spectrophotometric method. $3 \mathrm{~g}$ of the leaf sample was blended and then extracted with $10 \mathrm{ml}$ of $80 \%$ acetone, left for 15 mins, and the liquid portion decanted, centrifuged at 2,500 RPM for 3 mins. The supernatant was collected and its absorbance measured at $645 \mathrm{~nm}$ and $663 \mathrm{~nm}$, using spectrophotometer.

III. Results of APTI Computation

\begin{tabular}{|l|l|l|l|l|l|l|}
\hline S/N & Sample & RWC \% & Ascorbic mg/g & $\mathbf{P}^{\mathbf{H}}$ & Chlorophyll mg/g & APTI \\
\hline 1 & Ficus & 99.29 & 3.97 & 6.40 & 12.45 & 12.21 \\
\hline 2 & Hibiscus & 77.78 & 3.97 & 5.60 & 10.05 & 9.74 \\
\hline 3 & Ixora & 90.0 & 3.52 & 5.70 & 12.88 & 11.21 \\
\hline 4 & Phitis & 70.00 & 3.77 & 5.50 & 10.30 & 12.96 \\
\hline 5 & Toja & 80.00 & 4.40 & 5.40 & 11.10 & 15.26 \\
\hline 6 & Redrose & 77.78 & 4.40 & 6.40 & 8.70 & 14.42 \\
\hline
\end{tabular}

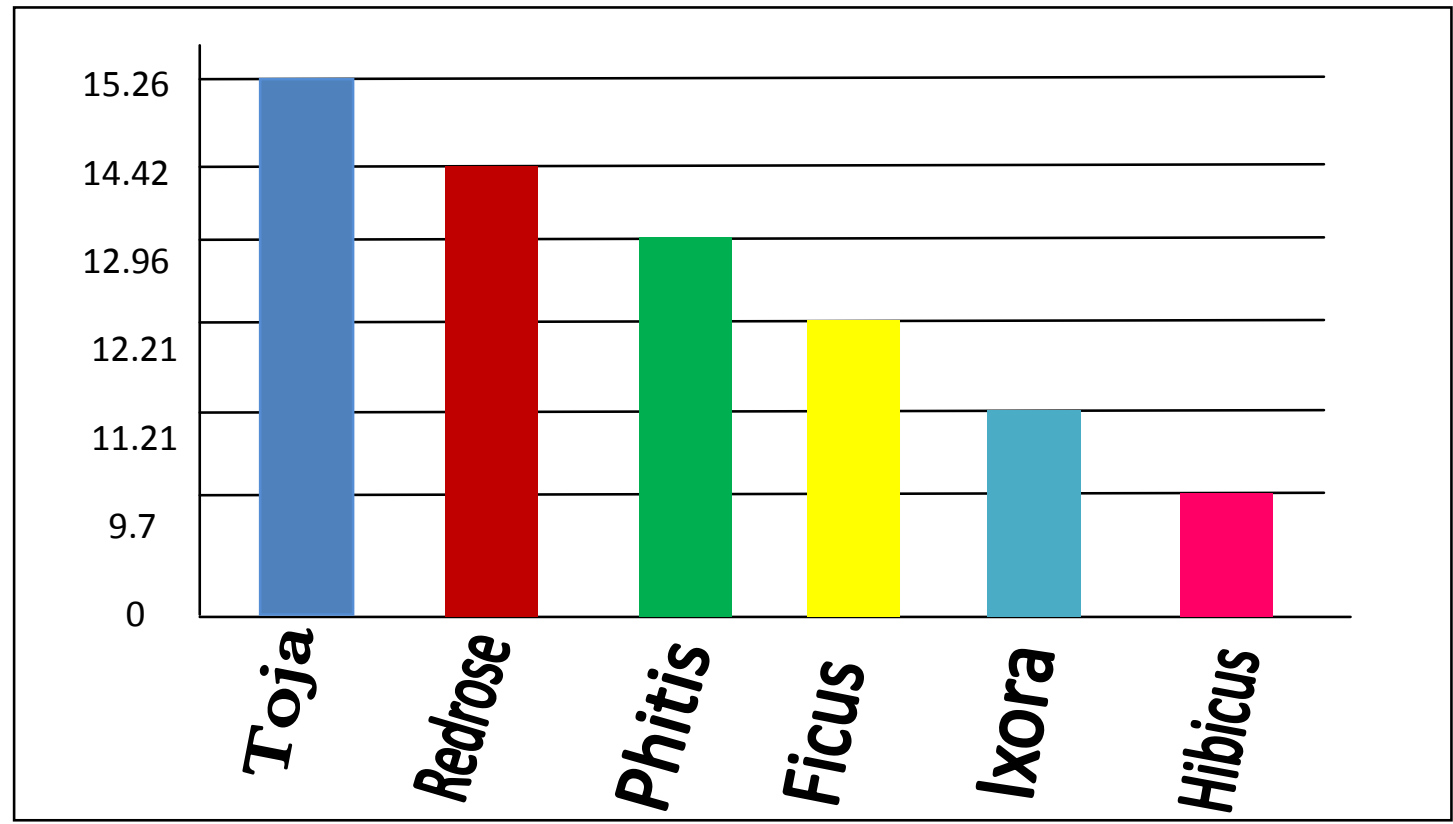

$\mathrm{APTI}=\mathrm{A}(\mathrm{T}+\mathrm{P})+\mathrm{R}$ 
A $=$ Ascorbic Acid

$\mathrm{T}=$ Total Chlorophyll

$\mathrm{P}=\mathrm{P}^{\mathrm{H}}$

$\mathrm{R}=$ Relative water content $(\mathrm{RWC})$

\subsection{DISCUSSION:}

\section{Discussion, Conclusion, And Recommendation}

Air pollution Tolerance Index (APTI) is used to determine the degree of sensitivity of plants to environmental air pollution. Singh(1991) suggested a method of determining Air Pollution Tolerance Index (APTI) by synthesizing the values of four different biochemical parameters-leaf extract $\mathrm{P}^{\mathrm{H}}$, ascorbic acid, total chlorophyll and relative water content. The result revealed that different plants respond differently to air pollution. This variation of the APTI can be attributed to the variation in any of the four biochemical parameters which govern the computation of the index. The relative water content (RWC) ranged between $70 \%$ in Phitis to 99.29\% Ficus, while ascorbic acid ranged from $3.5 \mathrm{mg} / \mathrm{l}$ in Ixora to 4.40 in Tora and Redrose respectively. In the computation of APTI using the formula,

$\mathrm{A}(\mathrm{T}+\mathrm{P})+\mathrm{R}, / 10, \mathrm{~A}$, which is the ascorbic acid is the multiplication factor and therefore determines to a great extent what the value of APTI would be. The same thing applies to T (total chlorophyll) and P (Leaf extract $\mathrm{P}^{\mathrm{H}}$ ). The higher the values of $\mathrm{P}$ and, or $\mathrm{T}$, the higher will be the APTI. Thus, Toja with highest value of total chlorophyll $(\mathrm{T})$, and ascorbic acid, recorded highest APTI of 15.26, followed by Redrose (APTI = 14.42) with $\mathrm{P}^{\mathrm{H}} 6.40$, ascorbic 4.40, Phitis $(\mathrm{APTI}=12.96)$, with $\mathrm{P}^{\mathrm{H}} 5.50$, ascorbic acid 3.77 and total chlorophyll 10.30 , Ficus recorded APTI value of 12.21, with $\mathrm{P}^{\mathrm{H}}$ 6.40, ascorbic acid 3.97, and total chlorophyll, 12.45, Ixora has APTI of 11.21 with total chlorophyll 12.88, ascorbic acid 3.52, $\mathrm{P}^{\mathrm{H}} 12.88$ and RWC $90 \%$. Hibiscus recorded the least APTI, 9.74.

Agarwalet al., (1991) classified plants into three categories of sensitivity. APTI value equal or less than 10 is considered sensitive, while APTI above 10 is considered tolerant and capable of withstanding air pollution load of significant value. In this present study, Toja is the most tolerant of the plants studied, followed by Redrose, Phitis, Ficus, Ixora, while Habiscus is sensitive to air pollution and recorded the least APTI. Sensitivity of plants is expressed by low APTI values, (Agrwalet al., 1991, Singh et al, 1991). The plants studied are commonly used in domestic and industrial landscaping in Enugu. Since APTI is a measure of tolerance ability of plants to environmental air pollution, it implies that Toja and Redrose plants are very ideal for use both as ornamental plants and phyto-remediating agents when air pollution is a major threat to environment

\subsection{CONCLUSION:}

Air pollution tolerance index determinations are important in the choice of plant for ornamental purposes and given the increased urbanization, industrialization with attendant traffic population in Enugu and other major cities in Nigeria, the possibility of increased air pollution cannot be ruled out. The results of present study become very useful in landscaping, for phyto-remediation of industrial polluted air environment, and microclimate modification. Tolerant species of plants should be considered in advance for use, when air pollution is high, while sensitive species should be used as bio-indicators of urban and rural air quality.

\subsection{RECOMMENDATION:}

It is therefore recommended that APTI determinations of plants be made prior to the use of such plants for ornamental purposes since the life span of plants is determined by its air pollution tolerance ability. Cultivation and use of Toja, Redrose, Phitis, Ficus, and Ixora for ornamental and phyto-remediating purposes should be encouraged because of their relative high APTI values, while Hibiscus should be planted as phytoindicator of air pollution in urban and industrial settings.

\section{References}

[1]. Agbaire, P.O (2009). Air pollution Tolerance Indices of some plants around Erhoike-kokori oil exploration site of Delta State, Nigeria. International Journal of Physical Sciences, 4:366-368.

[2]. Agbaire, P.O and Esiefarienrhe, E., (2009). Air pollution Tolerance Indices of some plants around Otorogun Gas Plants in Delta State, Nigeria. Journal of Applied Science and Environmental Management, 13: 11-14.

[3]. Agrawal, M., Pandey, J., Narayan, D. and Singh, S.K (1991). Air Pollution Tolerance Index of Plant. Journal of Environmental Management 31:45-49.

[4]. Arora, A. Sairam, R.K and Srivaastava, G.C (2002). Oxidative stress and Antioxidative System in Plants Current Analysis. 106:117120.

[5]. Association of Official Analytical Chemist (AOAC, 2005). In method of Analysis.

[6]. Conkline, P (2001). Recent Advances in the Role and Biosynthesis of ascorbic Acid in Plants. Plant Cell Environmenta, 24383-394

[7]. Enete, Ifeanyi. C., Ogbonna, C.E. (2012), Evaluation of Air pollution Tolerance Index (APTI) of some Selected Ornamental Shrubs in Enugu City, Nigeria. Journal of Environmental Science, Toxicology and Food Technology. ISSN: 2319-2402, ISBN: 2319-2399. Volume 1. Issue 2. PP 22-25. 
[8]. Gosh, G.K. (1992). Plants as Bio-Indicators of Automobile Exhaust Pollution - A case study of Sangi City. Journal of environmental pollution 1:26-28.

[9]. Lovett, G.M. and Lindberg, S.E. (1993). Atmosphereic Deposition and Canopy Interaction of Nitrogen in Forest. Journal of Forest Research23: 1603-16167.

[10]. Pandy, O.C. and Agarwal, M. (1994). Reduction in Chlorophyll Content in Leaves of Plants and Pollution 2:29-33.

[11]. Rabe, R. and Kreeb, K. H. (1980). Bioindication of air pollution by chlorophyll destruction in plants leaves. Oikos, 34: 163-163-167.

[12]. Siccama, T.I and Kousar, N.J. (1983). Acid Deposition and Forest Decline. Journal of Environmental Science Technology 19:488492.

[13]. Singh, S.N (1991). Attenuation of Automobile-Generated Air Pollution by High Plants. Plants and Pollution, 10, 1-2. 